\title{
Contribuições e adaptação da matriz canadense \\ para mensuração do retorno do investimento em pesquisa em saúde no âmbito da pós-graduação da Fundação Oswaldo Cruz
}

Contributions and adaptation of the Canadian matrix to measure the return on investment in health research under the Oswaldo Cruz Foundation graduate program

\author{
Marilyn Bonfim ${ }^{1}$ \\ Tania Araujo-Jorge ${ }^{2}$
}

Resumo: Este artigo apresenta a adaptação da matriz e indicadores para mensuração do retorno de investimento em pesquisa em saúde, para avaliação de um programa de indução à pesquisa, no âmbito de 16 cursos de doutorado da Fundação Oswaldo Cruz, uma das ações do Plano Brasil Sem Miséria. A matriz canadense se mostrou adequada para avaliação dos resultados do programa, em virtude dos atributos como flexibilidade, amplitude e profundidade, contemplando abordagens quantitativas e qualitativas. Para adaptação, foram consideradas as cinco dimensões avaliativas, bem como seus indicadores e métricas, critérios como validade, relevância, disponibilidade, custo e tempo de coleta de dados, orientaram a adaptação ao contexto brasileiro e ao objeto de estudo. Como resultado apresenta-se a matriz adaptada, os indicadores, assim como a fonte de coleta de dados e forma de análise dos dados. Ressalta-se a relevância deste estudo como contribuição à crescente demanda acadêmica e da sociedade civil por avaliação do investimento de recursos públicos em pesquisa.

Palavras-chave: Avaliação em saúde. Pesquisa em saúde. Pós-graduação. 
Abstract: This article presents the adaptation of the matrix and indicators for measuring the return on investment in health research, for the evaluation of a research induction program, within 16 doctoral courses of the Oswaldo Cruz Foundation, one of the actions of the Brasil Sem Miséria Plan. The Canadian matrix proved to be adequate for evaluating the results of the program, due to attributes such as flexibility, breadth and depth, including quantitative and qualitative approaches. For adaptation, the five evaluative dimensions were considered, as well as their indicators and metrics, criteria such as validity, relevance, availability, cost and time of data collection, guided the adaptation to the Brazilian context and the object of study. As a result, the adapted matrix, the indicators, as well as the data collection source and data analysis method are presented. The relevance of this study is highlighted as a contribution to the growing academic and civil society demand for evaluating the investment of public resources in research.

Keywords: Health evaluation. Health research. Postgraduate.

\author{
${ }^{1}$ Fundação Oswaldo Cruz | Instituto de Comunicação e Informação Científica e \\ Tecnológica em Saúde | Rio de Janeiro | RJ | Brasil. \\ Contato: mel.bonfim.fiocruz@gmail.com. ORCID: https://orcid.org/0000-0001-5634-1689. \\ ${ }^{2}$ Fundação Oswaldo Cruz | Laboratório de Inovações em Terapias, Educação e \\ Bioprodutos | Rio de Janeiro | RJ | Brasil. \\ Contato: taniaaj@ioc.fiocruz.br. ORCID: https://orcid.org/0000-0002-8233-5845.
}

DOI: http://dx.doi.org/10.1590/S1414-40772021000300008

Este é um artigo publicado em acesso aberto sob uma licença Creative Commons https://creativecommons.org/licenses/by-nc/4.0/ 


\section{Introdução}

O enfrentamento à extrema pobreza foi, nas duas últimas décadas, a principal agenda dos governos brasileiros. Em resposta ao levantamento do IBGE (2010) - que identificou cerca de 16 milhões de brasileiros vivendo abaixo da linha da pobreza, mesmo após anos de investimento em ações e programas sociais, especialmente o programa de transferência de renda condicionada, o Bolsa Família - o governo federal implementou, em 2011, o Plano Brasil Sem Miséria (PBSM) que teve como meta a erradicação da miséria em 4 anos (BRASIL, 2011; CAMPELLO; MELLO, 2014).

O Plano foi coordenado pelo então Ministério do Desenvolvimento Social e Combate à Fome (MDS) e articulou e integrou políticas, programas e ações sociais. Dentre suas diretrizes destaca-se "a articulação de ações de garantia de renda com ações voltadas à melhoria das condições de vida da população extremamente pobre, de forma a considerar a multidimensionalidade da situação da pobreza" (PAES-SOUSA, 2013; PAES-SOUSA; VAITSMAN, 2014).

A partir desta perspectiva, no campo da saúde, um dos pontos mais sensíveis para as pessoas que vivem em condições de negligência, a Fundação Oswaldo Cruz (Fiocruz), em parceria com o MDS e a Coordenação de Aperfeiçoamento de Pessoal de Nível Superior (CAPES), implementou um programa de indução à pesquisa em saúde relacionado à extrema pobreza, no período de 2012 a 2018, que contou com participação de 16 cursos de doutorado da Fiocruz.

O referido programa de indução à pesquisa teve como objetivo a geração de conhecimentos em saúde para mitigação dos problemas relacionados à extrema pobreza. Após o período de indução e apoio às pesquisas, os produtos foram apresentados em forma de teses, artigos científicos, produções técnicas e educacionais. Era preciso avaliar seus resultados e verificar se os objetivos esperados foram alcançados.

Para isso, foi realizada uma pesquisa avaliativa que teve três motivações/justificativas: a primeira, de cunho social, por abordar a questão da extrema pobreza e discutir a possibilidade de contribuição concreta por parte da academia para o enfrentamento da miséria; a segunda, de cunho acadêmico, se baseou na relevância do objeto de estudo, que carregava com si a responsabilidade de ser uma das primeiras iniciativas de aproximação entre academia e políticas sociais, sob fomento da CAPES; e a terceira, de cunho profissional atrelado ao compromisso institucional das autoras, de apresentar evidências sobre os resultados desta iniciativa, que estava diretamente relacionada à missão institucional da Fiocruz, de contribuir com a diminuição das desigualdades sociais. 
A pesquisa teve início com um estudo de avaliabilidade, publicado em 2021, que foi desenvolvido para construção e validação do modelo lógico do programa de indução e identificação das perguntas avaliativas dos stakeholders das três instituições envolvidas. Os resultados deste estudo indicaram que o programa era passível de avaliação e orientaram a decisão pela matriz e indicadores disponíveis no documento intitulado Making an Impact: A preferred Framework and Indicators to Measure Returns on Investment in Health Research (CAHS, 2009), aqui denominada Matriz CAHS, pois a principal questão avaliativa identificada foi se o investimento público neste programa indução à pesquisa em saúde retornou aos extremamente pobres e a sociedade de forma geral.

A escolha pela Matriz CAHS deve-se ao fato de que a mesma congrega diferentes abordagens metodológicas em um modelo de fácil compreensão e utilização, além de compreender um amplo menu de indicadores elaborado para contemplar as diversas necessidades avaliativas de diferentes programas, assim como abordagens quantitativas e qualitativas, se constituindo como um modelo prático, robusto, objetivo e, especialmente, aplicável.

Poucos estudos tratam da metodologia canadense de mensuração do retorno do investimento em pesquisa em saúde, a referida metodologia é citada em quatro artigos de revisão: Greenhalgh et al. (2016); Holmes et al. (2012); Penfield et al., (2014); Banzi et al., (2011), e em dois estudos internacionais e em estudo um nacional: Graham et al. (2012); Adam (2012); Tuesta (2015), respectivamente, nos quais a Matriz foi aplicada, o que muito contribuiu para a adaptação aqui apresentada.

Atributos como amplitude, profundidade e flexibilidade da Matriz CAHS demonstraram a coerência em utilizá-la para avaliação do referido programa de indução à pesquisa em saúde. Diversos aspectos reforçaram a viabilidade da aplicação ao contexto brasileiro e à intervenção estudada, como por exemplo, as similaridades entre: i) o princípio comum dos sistemas canadense e brasileiro, especialmente no que esse refere à universalidade da atenção primária em saúde; ii) similaridade entre as perspectivas do modelo de determinação social da saúde canadense e brasileiro, que consideram desde aspectos individuais até o contexto sociocultural, econômico e ambiental; e iii) semelhança entre a estruturação da pesquisa em saúde canadense e brasileira, sendo a primeira organizada em: pesquisa biomédica básica, pesquisa clínica aplicada, pesquisa de serviços de saúde e políticas, e pesquisa em população e saúde pública; e a segunda, organizada em: pesquisa básica, pesquisa aplicada e pesquisa em saúde pública e saúde coletiva. 
As convergências entre a Política Nacional de Ciência, Tecnologia e Inovação em Saúde brasileira e os referenciais teórico-metodológicos que subsidiaram o desenvolvimento da Matriz CAHS, como a premissa de que a pesquisa em saúde é constituída por conhecimentos, tecnologias e inovações, cuja aplicação pode resultar em melhorias na saúde da população, também orientaram a decisão.

Por fim, o ineditismo do programa de indução também foi considerado no processo decisório da escolha metodológica, uma vez que a Matriz CAHS pode ser considerada como um instrumento de aprendizagem, o que corrobora com um dos principais objetivos da avaliação, aprender com esse processo de aproximação entre a academia às políticas sociais, por meio da indução de pesquisa em saúde.

Este artigo tem o objetivo de apresentar as contribuições e a adaptação da Matriz CAHS realizadas para avaliar o programa de indução Fiocruz-CAPES-Brasil Sem Miséria e se justifica pela crescente demanda por avaliações sobre o retorno de investimentos públicos em pesquisa.

\section{Métodos}

A Matriz CAHS foi desenvolvida para ser utilizada como um roteiro de acompanhamento dos impactos de pesquisa em saúde em cinco dimensões avaliativas: 1) Avanço do Conhecimento; 2) Capacitação, aqui denominada Formação de Recursos Humanos;

3) Tomada de Decisão baseada em informação; 4) Impactos na Saúde; e 5) Impactos Socioeconômicos.

A partir dos critérios estabelecidos pela Academia Canadense de Ciências da Saúde, como validade, relevância, disponibilidade e custo dos dados, tempo de coleta e atribuição dos dados às pesquisas induzidas pelo programa é que se propôs a adaptação e as contribuições a Matriz, aqui apresentadas.

Em relação às dimensões avaliativas, três das cinco previstas na Matriz CAHS foram utilizadas na avaliação, a saber:

- Avanço do Conhecimento: busca identificar e qualificar a produção científica do investimento em pesquisa analisado. Essa dimensão apresenta métricas de qualidade, atividade, divulgação e aspecto estrutural do portfólio de pesquisa. Em geral, os indicadores são análises bibliométricas e análise da produção dos pesquisadores.

- Formação de Recursos Humanos: busca identificar o desenvolvimento e aprimoramento de habilidades de pesquisa em indivíduos e equipes. Abrange a capacidade atual de pesquisa por meio da equipe, considerando a próxima geração de pesquisadores.

- Tomada de decisão baseada em informação: busca identificar efeitos da pesquisa em saúde nas áreas da ciência e práticas públicas, clínicas e da tomada de decisão gerencial e do público em geral. 
A decisão do investimento em três dimensões foi fundamentada em função do escopo do programa de indução estudado, tempo decorrido pós-indução, tempo para desenvolvimento e conclusão da avaliação, assim como a viabilidade da coleta de dados.

As duas últimas dimensões, impactos na saúde e impactos socioeconômicos foram excluídas da avaliação, pois além de apresentarem o problema de atribuição acentuado, ou seja, dificuldade em atribuir uma relação causa-efeito, exigiria acompanhamento das mudanças durante um período maior de tempo.

Outra adaptação necessária pelos motivos supracitados, foi em relação às etapas finais da Matriz CAHS, as etapas de "adoção" e "resultados finais" foram suprimidas. Dessa forma, a adaptação proposta neste estudo foi representada de duas formas: a primeira, por meio de um quadro síntese (Quadro 1) e a segunda por meio do modelo lógico (Figura 1)

Quadro 1 - Matriz CAHS adaptada ao Programa Fiocruz-Capes-BSM

\begin{tabular}{|l|c|c|c|c|c|}
\hline \multicolumn{1}{|c|}{ MODELO } & \multirow{2}{|c|}{$\begin{array}{c}\text { P\&D em } \\
\text { Caúde }\end{array}$} & $\begin{array}{c}\text { Disseminação } \\
\text { Produtos } \\
\text { Primários }\end{array}$ & $\begin{array}{c}\text { Produtos } \\
\text { Secundários }\end{array}$ & $\begin{array}{c}\text { Adoção } \\
\text { Resultados } \\
\text { Finais }\end{array}$ \\
\hline Avanço do Conhecimento & $*$ & $*$ & $*$ & -- \\
\hline Formação de Recursos Humanos & $*$ & $*$ & $*$ & -- & -- \\
\hline $\begin{array}{l}\text { Tomada de Decisão baseada em } \\
\text { informação/evidência }\end{array}$ & $*$ & $*$ & $*$ & -- \\
\hline Impactos na Saúde & -- & -- & -- & - \\
\hline Impactos Socioeconômicos & -- & -- & -- & - \\
\hline
\end{tabular}

Fonte: Elaborado pelas autoras 
Figura 1 - Modelo Lógico da Adaptação da Matriz CAHS ao Programa de Indução à Pesquisa em Saúde:

\section{Fiocruz-CAPES-Brasil Sem Miséria}

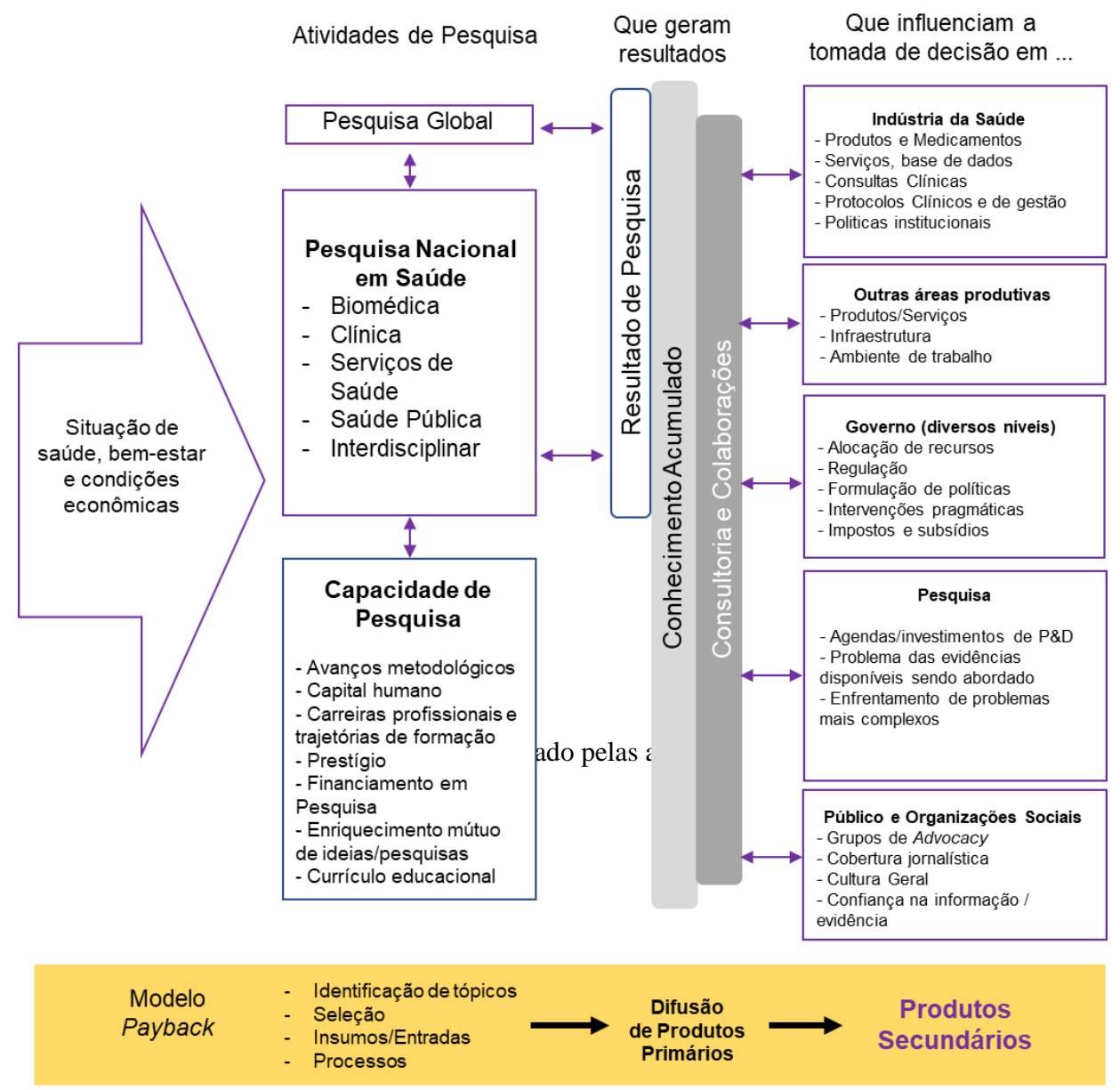

Para definição do conjunto de indicadores do menu proposto pela Matriz CAHS, foram utilizados os diagramas dos quatro pilares da pesquisa em saúde: pesquisa biomédica, pesquisa clínica aplicada, pesquisa em serviços de saúde e população e pesquisa em saúde pública e ainda na pesquisa transversal, de forma a identificar onde indicadores ou métricas para esses efeitos deveriam ser concentrados.

As orientações da CAHS foram norteadoras do processo, especialmente os alertas quanto ao uso inadequado da Matriz, como a busca por, apenas, resultados positivos e a dupla contagem dos resultados e efeitos das pesquisas.

O conjunto de categorias, subcategorias e indicadores foram classificados em:

- adotados: como descritos na Matriz;

- adaptados: descritos na Matriz, mas adequados às características do programa avaliado;

- incluídos: ausentes na Matriz e inseridos para obter dados relevantes para responder à questão da pesquisa; e 
- excluídos: presentes na Matriz e suprimidos, por não estarem relacionados aos objetivos da avaliação ou por não terem aplicação viável.

Da mesma forma, adaptou-se ao contexto da pesquisa os níveis que a Matriz busca descrever: individual, institucional, regional/estadual, nacional e internacional. Neste estudo os níveis definidos foram, apenas, os níveis individual e institucional, por se tratar de um estudo de caso (YIN, 2001).

\section{Resultados e discussão}

Os resultados apresentados a seguir foram organizados pelas dimensões avaliativas que compuseram o estudo. O Quadro 2 sintetiza as categorias e os indicadores, os Quadros 3, 4 e 5 apresentam de forma detalhada a descrição dos indicadores, a fonte de dados e suas limitações e a forma que os dados foram analisados.

Quadro 2 - Síntese de Indicadores por Dimensão e Categoria Avaliativas

\begin{tabular}{|c|c|c|}
\hline Dimensão Avaliativa & Categoria Avaliativa & Indicadores \\
\hline \multirow{5}{*}{$\begin{array}{l}\text { Formação de Recursos } \\
\text { Humanos }\end{array}$} & Pessoal & Número de Doutores Formados \\
\hline & \multirow{2}{*}{ Formativa } & Seleção \\
\hline & & Formação e Acompanhamento Institucional \\
\hline & \multirow[t]{2}{*}{ Indicadores Aspiracionais } & $\begin{array}{l}\text { Capacidade de Absorção no Mercado de } \\
\text { Trabalho }\end{array}$ \\
\hline & & Pós-Doutoramento \\
\hline \multirow{5}{*}{ Avanço do Conhecimento } & \multirow{2}{*}{ Atividade } & $\begin{array}{l}\text { Contagem de Publicação: Teses, Artigos, } \\
\text { Livros e Capítulos de Livro }\end{array}$ \\
\hline & & Número e Descrição de Produções Técnicas \\
\hline & \multirow{3}{*}{ Qualidade } & Publicação em Meios de Alta Qualidade \\
\hline & & $\begin{array}{l}\text { Contagem de Citações da Produção Científica: } \\
\text { Artigos, Livros e Capítulos de Livro }\end{array}$ \\
\hline & & $\begin{array}{l}\text { Análise Qualitativa das Teses à luz da temática } \\
\text { da indução à pesquisa }\end{array}$ \\
\hline \multirow{2}{*}{$\begin{array}{c}\text { Tomada de Decisão } \\
\text { baseada em informação e } \\
\text { evidências }\end{array}$} & $\begin{array}{l}\text { Educação Relacionada à } \\
\text { Saúde }\end{array}$ & Produtos Educacionais e Informativos \\
\hline & $\begin{array}{c}\text { Indústria de Produtos para } \\
\text { Saúde }\end{array}$ & Número de Patentes e Softwares Registrados \\
\hline
\end{tabular}

Fonte: Elaborado pelas autoras 
Quadro 3: Dimensão Avaliativa: Formação de Recursos Humanos

\begin{tabular}{|c|c|c|c|c|}
\hline $\begin{array}{l}\text { Categoria } \\
\text { Avaliativa }\end{array}$ & Indicador & Descrição do Indicador & Fontes de Dados e Limitações & Análise de Dados \\
\hline Pessoal & $\begin{array}{l}\text { Doutores } \\
\text { Formados }\end{array}$ & $\begin{array}{l}\text { Número de doutorandos } \\
\text { (recém-doutores) que } \\
\text { concluíram as pesquisas } \\
\text { alinhadas ao BSM }\end{array}$ & Fonte: Dados Oficiais da VPEIC/Fiocruz & $\begin{array}{l}\text { Descritiva } \\
\text { - Número de alunos bolsistas. } \\
\text { - Número de alunos não bolsistas. } \\
\text { Espera-se: } \\
\text { - identificar o número de doutorandos que } \\
\text { participaram do programa de indução, com ou sem } \\
\text { bolsa de estudos. } \\
\text { Comparativa: (acima ou abaixo do esperado): } \\
\text { - Número de alunos matriculados x formados. } \\
\text { Espera-se: } \\
\text { - identificar se o percentual de alunos concluintes é } \\
\text { de } 80 \% \text { dos alunos matriculados. } \\
\text { Referência: - Taxa de } 80 \% \text { de conclusão na pós- } \\
\text { graduação stricto sensu, Colombo (2019) e } \\
\text { Fernandes } \text { et al. (2017). }\end{array}$ \\
\hline Formativa & Seleção & $\begin{array}{l}\text { Clareza quanto aos } \\
\text { critérios de seleção e } \\
\text { produtos esperados no } \\
\text { processo seletivo. }\end{array}$ & $\begin{array}{l}\text { Fontes: Websites e Secretaria Acadêmica } \\
\text { das Pós-Graduações } \\
\text { Limitações: } \\
\text {-Ausência dos editais anteriores nos } \\
\text { websites das pós-graduações } \\
\text {-Não retorno da Secretaria Acadêmica das } \\
\text { Pós-Graduações }\end{array}$ & $\begin{array}{l}\text { Documental Descritiva: Análise dos Editais do } \\
\text { processo seletivo para a indução BSM } \\
\text { Espera-se: } \\
\text { - identificar a existência de editais de seleção } \\
\text { específicos para o programa de indução; } \\
\text { - identificar critérios de seleção claros e produtos } \\
\text { esperados, descritos de forma explícita no } \\
\text { documento. }\end{array}$ \\
\hline Formativa & Seleção & $\begin{array}{l}\text { Clareza quanto aos } \\
\text { critérios de seleção e } \\
\text { produtos esperados no } \\
\text { processo seletivo. }\end{array}$ & $\begin{array}{l}\text { Fonte: Questionário } \\
\text { Questão: } \\
\text { "O edital de seleção estava claro quanto } \\
\text { aos critérios de entrada e produtos } \\
\text { esperados referentes ao programa BSM?" } \\
\text { Limitações: } \\
\text { - Baixo número de respondentes } \\
\text { - Veracidade das respostas }\end{array}$ & $\begin{array}{l}\text { Descritiva } \\
\text { Esperava-se: } \\
\text { - identificar, a partir da percepção do egresso, se os } \\
\text { compromissos com o programa de indução } \\
\text { estavam claros, desde o processo seletivo. } \\
\text { Referência: documento aprovado pela Câmara } \\
\text { Técnica de Ensino da Fiocruz, com orientações } \\
\text { para o programa de indução BSM aos programas } \\
\text { de pós-graduação (2011). }\end{array}$ \\
\hline
\end{tabular}




\begin{tabular}{|c|c|c|c|c|}
\hline Formativa & Formação & $\begin{array}{l}\text { Realização de disciplinas } \\
\text { sobre a temática das } \\
\text { desigualdades, extrema } \\
\text { pobreza e relação com a } \\
\text { saúde }\end{array}$ & $\begin{array}{l}\text { Fonte: Questionário } \\
\text { Questões: } \\
\text { - "Você cursou disciplinas que trataram da } \\
\text { temática da desigualdade sociais, extrema } \\
\text { pobreza e suas relações com a saúde?” } \\
\text { - "Essa(s) disciplina(s) foram cursadas em } \\
\text { qual programa de pós-graduação?” } \\
\text { - "A disciplina cursada atendeu sua } \\
\text { expectativa quanto ao aprofundamento elou } \\
\text { discussão sobre a questão da } \\
\text { desigualdadelpobreza, contribuindo para } \\
\text { sua pesquisa?” } \\
\text { Limitações: } \\
\text { - Baixo número de respondentes } \\
\text { - Veracidade das respostas }\end{array}$ & $\begin{array}{l}\text { Descritiva } \\
\text { Espera-se: } \\
\text {-identificar se os doutores cursaram disciplinas } \\
\text { relacionadas à temática da indução (saúde e } \\
\text { extrema pobreza) e se, na percepção deles, estas } \\
\text { contribuíram para o processo formativo. } \\
\text { Referência: não houve orientação institucional para } \\
\text { oferta de disciplinas sobre a temática, contudo em } \\
\text { análise exploratória identificou-se a oferta destas } \\
\text { disciplinas. }\end{array}$ \\
\hline \multirow[t]{2}{*}{ Formativa } & \multirow[t]{2}{*}{ Formação } & $\begin{array}{l}\text { Realização de seminários } \\
\text { e outras formas de } \\
\text { acompanhamento das } \\
\text { pesquisas induzidas }\end{array}$ & $\begin{array}{l}\text { Fonte: Questionário } \\
\text { Questões: } \\
\text { - “A partir da sua experiência como aluno } \\
\text { de doutorado no Programa Fiocruz- } \\
\text { CAPES-BSM, você afirmaria que } \\
\text { institucionalmente (a coordenação geral de } \\
\text { pós-graduação elou o programa de pós- } \\
\text { graduação) promoveram ações para o } \\
\text { acompanhamento e a alinhamento das } \\
\text { pesquisas ao contexto do Brasil Sem } \\
\text { Miséria?” } \\
\text { - “Quais ações você destacaria?”, } \\
\text { Limitações: } \\
\text { - Baixo número de respondentes } \\
\text { - Veracidade das respostas }\end{array}$ & $\begin{array}{l}\text { Descritiva } \\
\text { Esperava-se: } \\
\text { - identificar se houve acompanhamento } \\
\text { institucional na forma prevista e/ou além da forma } \\
\text { prevista; } \\
\text { - identificar qual(is) forma(s) de acompanhamento } \\
\text { institucional os doutores reconheceram. } \\
\text { Referência: documento aprovado pela Câmara } \\
\text { Técnica de Ensino da Fiocruz, com definição que } \\
\text { os projetos induzidos seriam acompanhados por } \\
\text { meio da realização de seminários (2011) - Anexo } \\
\text { II desta tese. }\end{array}$ \\
\hline & & $\begin{array}{l}\text { Adequação e suficiência } \\
\text { do acompanhamento das } \\
\text { pesquisas induzidas }\end{array}$ & $\begin{array}{l}\text { Fonte: Questionário } \\
\text { Questões: } \\
\text { - "Mais ações [de acompanhamento] } \\
\text { foram/seriam necessárias?” }\end{array}$ & $\begin{array}{l}\text { Descritiva } \\
\text { Espera-se: } \\
\text { - identificar se a estratégia de acompanhamento } \\
\text { definida institucionalmente foi adequada, na } \\
\text { perspectiva dos doutores formados; }\end{array}$ \\
\hline
\end{tabular}




\begin{tabular}{|c|c|c|c|c|}
\hline & & & $\begin{array}{l}\text { [em caso positivo] - "Que ações você } \\
\text { entende que deveriam ter sido promovidas } \\
\text { para o acompanhamento dos } \\
\text { doutorandos?" } \\
\text { Limitações: } \\
\text { - Baixo número de respondentes } \\
\text { - Veracidade das respostas }\end{array}$ & $\begin{array}{l}\text { - identificar se as ações foram suficientes para } \\
\text { atender as necessidades dos doutores formados; e } \\
\text { - identificar as propostas dos egressos de ações de } \\
\text { acompanhamento. } \\
\text { Referência: documento aprovado pela Câmara } \\
\text { Técnica de Ensino da Fiocruz, com definição que } \\
\text { os projetos induzidos seriam acompanhados por } \\
\text { meio da realização de seminários (2011). }\end{array}$ \\
\hline Aspiracional & $\begin{array}{l}\text { Inserção } \\
\text { profissional dos } \\
\text { Doutores } \\
\text { formados }\end{array}$ & $\begin{array}{l}\text { Capacidade de absorção } \\
\text { no mercado de trabalho } \\
\text { e/ou melhoria da situação } \\
\text { empregatícia }\end{array}$ & $\begin{array}{l}\text { Fonte: Currículo Lattes } \\
\text { Limitação: } \\
\text { Não atualização do Currículo Lattes. }\end{array}$ & $\begin{array}{l}\text { Descritiva } \\
\text { Esperava-se: } \\
\text { - identificar se o doutoramento contribuiu para a } \\
\text { atuação profissional do doutor formado. } \\
\text { - identificar se os doutores estão inseridos no } \\
\text { mercado de trabalho. } \\
\text { Referências: } \\
\text { - a taxa de desocupação de doutores no Brasil é de } \\
\text { 25\% (MEIRA, 2019). O contexto econômico e } \\
\text { político brasileiro não contribuiu para absorção de } \\
\text { recém-doutores no mercado de trabalho. } \\
\text { - 61,5\% dos doutores no Brasil atuam na área de } \\
\text { ensino e pesquisa (CNPq, 2017). }\end{array}$ \\
\hline Aspiracional & $\begin{array}{l}\text { Prosseguimento } \\
\text { dos estudos no } \\
\text { âmbito de pós- } \\
\text { doutoramento }\end{array}$ & $\begin{array}{l}\text { Realização do pós- } \\
\text { doutorado e temática } \\
\text { prosseguimento de } \\
\text { estudos sobre a temática } \\
\text { que envolve a pobreza }\end{array}$ & $\begin{array}{l}\text { Fonte: Currículo Lattes } \\
\text { Limitação: } \\
\text { Não atualização do Currículo Lattes. }\end{array}$ & $\begin{array}{l}\text { Descritiva } \\
\text { Esperava-se: } \\
\text { - identificar se os doutores formados seguiram ou } \\
\text { desejam seguir com estudos/pesquisas no pós- } \\
\text { doutorado. }\end{array}$ \\
\hline
\end{tabular}

Fonte: Elaborada pelas autoras, a partir da adaptação da Matriz Canadense de Mensuração de Retorno do Investimento em Pesquisa em Saúde 
Quadro 4 - Dimensão Avaliativa: Avanço do Conhecimento

\begin{tabular}{|c|c|c|c|c|}
\hline $\begin{array}{l}\text { Categoria } \\
\text { Avaliativa }\end{array}$ & Indicador & Descrição do Indicador & Fontes de Dados e Limitações & Análise de Dados \\
\hline Atividade & Produção Científica & $\begin{array}{l}\text { Contagem de Publicação: } \\
\text { Artigo em Periódico } \\
\text { Livros } \\
\text { Capítulos de Livros } \\
\text { Teses }\end{array}$ & $\begin{array}{l}\text { Fonte: Currículo Lattes } \\
\text { Limitação: } \\
\text { Não atualização do Currículo Lattes. }\end{array}$ & $\begin{array}{l}\text { Comparativa (acima ou abaixo do esperado) } \\
\text { Esperava-se: } \\
\text { - identificar ao menos } 1 \text { artigo publicado em } \\
\text { periódico pelos concluintes sobre a temática da } \\
\text { pesquisa e/ou em co-autoria do/a orientador/a da } \\
\text { tese; e } \\
\text { - identificar a produção de } 74 \text { teses, considerando o } \\
\text { taxa de conclusão admitida ( } 80 \%) \text {. } \\
\text { Referências: } \\
\text { - Regimento Geral da Pós-Graduação da Fiocruz, } \\
\text { obrigatoriedade de submissão/publicação de um } \\
\text { artigo para defesa de doutorado; } \\
\text { - Taxa de } 80 \% \text { de conclusão na pós-graduação stricto } \\
\text { sensu, Colombo (2019) e Fernandes et al. (2017). }\end{array}$ \\
\hline Qualidade & $\begin{array}{l}\text { Qualis das publicações na } \\
\text { área que a pós-graduação } \\
\text { está inserido na CAPES }\end{array}$ & $\begin{array}{l}\text { Verificação do Qualis dos } \\
\text { Periódicos }\end{array}$ & $\begin{array}{l}\text { Fontes: } \\
\text { Currículo Lattes } \\
\text { Plataforma Sucupira - Webqualis } \\
\text { Limitação: } \\
\text { Não atualização do Currículo Lattes. }\end{array}$ & $\begin{array}{l}\text { Comparativa (acima ou abaixo do esperado) } \\
\text { Esperava-se: } \\
\text { - identificar publicação de artigos em periódicos com } \\
\text { Qualis B1, na área de avaliação de cada pós- } \\
\text { graduação. } \\
\text { Referência: A partir dos Regimentos das Pós- } \\
\text { graduações, considerando que a maior exigência } \\
\text { encontrada foi a publicação em periódicos Qualis } \\
\text { B1, este ficou estabelecido como parâmetro mínimo } \\
\text { de qualidade, para área de avaliação de cada } \\
\text { doutorado. }\end{array}$ \\
\hline
\end{tabular}




\begin{tabular}{|c|c|c|c|c|}
\hline Qualidade & Número de Citações & $\begin{array}{l}\text { Verificação do Qualis dos } \\
\text { Periódicos }\end{array}$ & $\begin{array}{l}\text { Fontes: } \\
\text { Currículo Lattes } \\
\text { Scholar Google } \\
\text { Limitação: } \\
\text { Não atualização do Currículo Lattes. }\end{array}$ & $\begin{array}{l}\text { Descritiva } \\
\text { - Número de citações da produção científica: } \\
\text { Artigos, Capítulos de Livros e Livros. } \\
\text { Espera-se: } \\
\text { - identificar o número citações da produção científica } \\
\text { produto do programa de indução. } \\
\text { Comparativa (acima ou abaixo do esperado) }\end{array}$ \\
\hline Qualidade & $\begin{array}{c}\text { Produção Acadêmica } \\
\text { Teses }\end{array}$ & $\begin{array}{l}\text { Abordagem sobre a } \\
\text { temática da extrema } \\
\text { pobreza e sua relação com a } \\
\text { saúde e a pesquisa realizada }\end{array}$ & $\begin{array}{l}\text { Fonte: Teses } \\
\text { Limitação: Não disponibilização das } \\
\text { Teses em Acesso Aberto e/ou } \\
\text { Domínio Público }\end{array}$ & $\begin{array}{l}\text { Análise Textual-Discursiva } \\
\text { A partir do roteiro apresentado no item 3.2.2.1. } \\
\text { buscou responder as seguintes questões: } \\
\text { - houve alinhamento à perspectiva multidimensional } \\
\text { da pobreza orientadora do Plano Brasil Sem Miséria? } \\
\text { - qual forma e/ou ênfase foi dada à perspectiva da } \\
\text { extrema pobreza nas teses? } \\
\text { - quais temáticas de saúde foram objetos de estudo } \\
\text { das teses? } \\
\text { Esperava-se: } \\
\text { - que as teses tenham abordado a perspectiva } \\
\text { multidimensional da pobreza; } \\
\text { - que as teses tenham discutido a pobreza como } \\
\text { determinante social da saúde; } \\
\text { - que as teses estejam centradas em Doenças da } \\
\text { Pobreza. } \\
\text { Referência: os referenciais teóricos que subsidiaram } \\
\text { esta análise serão apresentados no roteiro } \\
\text { supracitado. }\end{array}$ \\
\hline
\end{tabular}




\begin{tabular}{|c|c|c|c|c|}
\hline Atividade & Produção Técnica & $\begin{array}{l}\text { Número e descrição dos } \\
\text { produtos técnicos }\end{array}$ & $\begin{array}{l}\text { Fonte: Teses e Questionário } \\
\text { Questões: } \\
\text { - "Dentre os produtos de sua pesquisa } \\
\text { era esperado a tese, para obtenção do } \\
\text { título de Doutor, e também produtos } \\
\text { técnicos relacionados ao Programa } \\
\text { Brasil Sem Miséria. Qual produto } \\
\text { técnico foi resultado da sua } \\
\text { pesquisa?" } \\
\text { - "O produto técnico informado na } \\
\text { questão anterior foi aplicado para } \\
\text { além do período de doutoramento?" } \\
\text { [em caso positivo] - " Como foi a } \\
\text { aplicação do produto técnico de sua } \\
\text { pesquisa?" } \\
\text { [em caso negativo] - "Qual motivo } \\
\text { você acredita que dificultou ou } \\
\text { impossibilitou a aplicação do produto } \\
\text { técnico da sua tese?" } \\
\text { Limitações: } \\
\text { - Não disponibilização das Teses em } \\
\text { Acesso Aberto e/ou Domínio Público, } \\
\text { por conta de embargos } \\
\text { - Não apresentação do produto técnico } \\
\text { na tese } \\
\text { - Baixo número de respondentes ao } \\
\text { questionário } \\
\text { - Veracidade das respostas }\end{array}$ & $\begin{array}{l}\text { Documental Descritiva: Análise das Teses } \\
\text { Espera-se: } \\
\text { - identificar qual o tipo de produto técnico foi } \\
\text { apresentado em cumprimento a exigência da indução } \\
\text { (nota técnica, material informativo, material } \\
\text { didático); } \\
\text { - identificar se o produto técnico foi aplicado; } \\
\text { - identificar a forma de aplicação, quando for o caso; } \\
\text { e } \\
\text { - identificar o motivo, que o egresso atribuiu a não } \\
\text { aplicação do produto técnico. } \\
\\
\text { Referência: documento aprovado pela Câmara } \\
\text { Técnica de Ensino da Fiocruz, com definição de que } \\
\text { um dos compromissos dos doutores era produzir ao } \\
\text { menos um produto técnico relacionado aos serviços } \\
\text { públicos focalizados no BSM, ou ao público-alvo do } \\
\text { BSM ou aos territórios em que o BSM identificou } \\
\text { pessoas vivendo abaixo da linha da extrema pobreza } \\
\text { (2011). }\end{array}$ \\
\hline
\end{tabular}

Fonte: Elaborada pelas autoras, a partir da adaptação da Matriz Canadense de Mensuração de Retorno do Investimento em Pesquisa em Saúde 
Quadro 5 - Dimensão Avaliativa: Tomada de Decisão baseada em Informação/Evidências

\begin{tabular}{|c|c|c|c|c|c|}
\hline $\begin{array}{c}\text { Categoria } \\
\text { Avaliativa }\end{array}$ & $\begin{array}{c}\text { Subcategoria } \\
\text { Avaliativa }\end{array}$ & Indicador & $\begin{array}{l}\text { Descrição do } \\
\text { Indicador }\end{array}$ & Fontes de Dados e Limitações & Análise dos Dados \\
\hline $\begin{array}{l}\text { Educação } \\
\text { relacionada à } \\
\text { Saúde }\end{array}$ & $\begin{array}{l}\text { Produtos } \\
\text { Educacionais }\end{array}$ & $\begin{array}{l}\text { Produtos } \\
\text { Educacionais } \\
\text { Registrados }\end{array}$ & $\begin{array}{l}\text { Número de Produtos } \\
\text { Educacionais } \\
\text { Registrados }\end{array}$ & $\begin{array}{l}\text { Fonte: Currículo Lattes } \\
\text { Limitação: } \\
\text { Não atualização do Currículo } \\
\text { Lattes. }\end{array}$ & $\begin{array}{l}\text { Descritiva } \\
\text { Número de produtos educacionais registrados } \\
\text { Esperava-se: } \\
\text { - identificar os produtos educacionais, frutos das } \\
\text { pesquisas, que foram registrados. } \\
\text { Referência: documento aprovado pela Câmara } \\
\text { Técnica de Ensino da Fiocruz, com definição de } \\
\text { que registro de patentes seria uma das estratégias } \\
\text { para atender ao compromisso firmado com o } \\
\text { programa de indução (2011). }\end{array}$ \\
\hline $\begin{array}{l}\text { Produtos para } \\
\text { Saúde }\end{array}$ & Patentes & $\begin{array}{l}\text { Patentes } \\
\text { Registradas }\end{array}$ & $\begin{array}{l}\text { Número de Patentes } \\
\text { Registradas }\end{array}$ & $\begin{array}{l}\text { Fonte: Currículo Lattes } \\
\text { Limitação: } \\
\text { Não atualização do Currículo } \\
\text { Lattes. }\end{array}$ & $\begin{array}{l}\text { Descritiva } \\
\text { Número de patentes registradas } \\
\text { Esperava-se: } \\
\text { - identificar as patentes, frutos das pesquisas, que } \\
\text { foram registradas. } \\
\text { Referência: documento aprovado pela Câmara } \\
\text { Técnica de Ensino da Fiocruz, com definição de } \\
\text { que registro de patentes seria uma das estratégias } \\
\text { para atender ao compromisso firmado com o } \\
\text { programa de indução (2011). }\end{array}$ \\
\hline
\end{tabular}

Fonte: Elaborada pelas autoras, a partir da adaptação da Matriz Canadense de Mensuração de Retorno do Investimento em Pesquisa em Saúde 
A seguir são apresentadas as fontes de dados, assim como a proposta de análise dos mesmos, propostos para essa adaptação:

- Plataforma Sucupira/CAPES: base de referência do Sistema Nacional de PósGraduação (SNPG), dispositivo no qual se realiza a coleta de informação, análises e avaliações dos programas de pós-graduação brasileiros.

- Qualis: sistema de classificação da produção científica brasileira, baseada nos artigos publicados em periódicos de todos os programas de pós-graduações do país.

Reconhecemos que há fortes críticas ao próprio sistema de avaliação da produção científica dos programas de pós-graduação (GABARDO; HACHEM; HAMADA, 2018; SILVA, 2009), contudo esse é o parâmetro vigente ao qual a academia está submetida.

- Plataforma Lattes/CNPq: base de dados de Currículos, de Grupos de pesquisa e de Instituições. Tornou-se o padrão nacional no registro da vida pregressa e atual dos estudantes e pesquisadores do país.

Reconhecemos que há limitações importantes ao uso dos dados desta plataforma, especialmente a não atualização dos dados pelos pesquisadores e a fidedignidade dos dados, uma vez que o preenchimento é autodeclarado.

- Repositório ARCA da Fiocruz: repositório institucional regido pela Política de Acesso Aberto ao Conhecimento, que busca garantir à sociedade o acesso gratuito, público e aberto ao conteúdo integral de toda obra intelectual produzida pela Fiocruz.

- Questionário: instrumento de coleta de dados, survey, (MARCONI; LAKATTOS, 2008), aplicado aos egressos do programa BSM, por meio da plataforma GoogleForms.

Este instrumento foi testado e validado por 3 alunos, de 3 programas de pós-graduação diferentes, as contribuições foram acatadas e o questionário disponibilizado, sem possibilidade de identificação do respondente, em atendimento à solicitação dos egressos que validaram o questionário e apontaram, que sem identificação, as respostas seriam mais fidedignas.

A análise de dados, por meio da triangulação, de acordo com Minayo (2005), em uma primeira dimensão é utilizada para avaliação aplicada a programas, projetos e afins, o que vem ao encontro do estudo apresentado.

A teses foram analisadas por meio da abordagem de análise textual-discursiva de Moraes e Galiazzi (2016), que fundamentam a análise nos estudos do campo Fenomenologia e propõem um "movimento interpretativo de caráter hermenêutico", a referida análise opera com significados construídos a partir de um conjunto de textos.

Todo esse esforço, motivado por compromisso social, acadêmico e institucional, revela o grau de investimento e detalhamento para a construção de metodologias, escolhas de 
indicadores e critérios, fontes de dados e tipos de análise que sejam capazes de mensuram o retorno do investimento público em pesquisa em saúde aliada às políticas sociais.

Esse tipo de estudo se propõe a contribuir para que outros programas e/ou ações de investimento em pesquisa sejam realizados e avaliados, na perspectiva de aprendizagem e contínua melhoria, evidenciando que é possível dar respostas e construir soluções para a realidade de um país como o Brasil, um dos mais desiguais do mundo, que pouco valoriza a ciência e acumula um lamentável histórico de mal-uso de recursos públicos.

\section{Considerações}

Este artigo apresentou o esforço de adaptar a Matriz de mensuração do retorno de investimento em pesquisa em saúde da Academia Canadense de Ciências da Saúde, para aplicála ao programa de indução à pesquisa, fruto da cooperação tripartite entre Fiocruz, CAPES e MDS.

Foram definidas três dimensões avaliativas: Avanço do Conhecimento, Formação de Recursos Humanos e Tomada de Decisão baseada em informação/evidência e seus respectivos indicadores, a partir de critérios claros e objetivos. O principal investimento desta adaptação foi na dimensão Formação de Recursos Humanos, uma vez que a Matriz canadense não foi projetada para avaliação de programas de formação de pesquisadores, como é o caso das pósgraduações que participaram desta indução.

Nesta dimensão foi incluída a categoria "formativa" com indicadores de processo seleção, formação e produção acadêmica e técnica. Neste sentido, este artigo é uma proposta metodológica, com caráter inovador, que se propõe a identificar e descrever os resultados do programa de indução, a partir da triangulação de dados, para responder se o programa alcançou ou não os resultados esperados.

Dessa forma, espera-se que outras pesquisas avaliativas possam fazer uso deste trabalho em programas com escopo semelhante.

Por fim, ressalta-se a relevância deste estudo como contribuição à crescente demanda da academia e da sociedade civil por avaliação do investimento de recursos públicos em pesquisa. 


\section{Referências}

ADAM, Paula et al. Assessment of the impact of a clinical and health services research call in Catalonia. Research Evaluation, Reino Unido, v. 21, n. 4, p. 319-328, 2012. Disponível em: https://doi.org/10.1093/reseval/rvs024. Acesso em: 19 mar. 2018.

BANZI, Rita et al. Conceptual frameworks and empirical approaches used to assess the impact of health research: an overview of reviews. Health Research Policy and Systems, Califórnia, 2011.

BRASIL. Decreto no 7.492, de 02 de junho de 2011. Institui o Plano Brasil Sem Miséria. Diário Oficial, Brasília-DF, 3 jun. 2011. Seção 1, p. 6. Disponível em: http://pesquisa.in.gov.br/imprensa/jsp/visualiza/index.jsp?jornal=1\&pagina=6\&data=03/06/20 11. Acesso em: 19 mar. 2018.

CAHS - CANADIAN ACADEMY OF HEALTH SCIENCES. Making an impact: a preferred framework and indicators to measure returns on investment in health research. Canadian, 2009.

CAMPELLO, Terezza; MELLO, Janine. O processo de formulação e os desafios do plano Brasil Sem Miséria: por um país rico e com oportunidades para todos. In: BRASIL. Ministério do Desenvolvimento Social e Combate à Fome. O Brasil sem miséria. Brasília: MDS, 2014.

GABARDO, Emerson; HACHEM, Daniel; HAMADA, Guilherme. Sistema Qualis: análise crítica da política de avaliação de periódicos científicos no Brasil. Revista do Direito, Santa Cruz do Sul, v. 1, n. 54, p. 144-185, jan./abr. 2018.

GRAHAM, Kathryn et al. Evaluating health research impact: development and implementation of the alberta innovates-health solutions impact framework. Res Evaluation, Reino Unido, n. 21, p. 354-67, 2012.

GREENHALGH, Trisha et al. Research impact: a narrative review. BMC Medicine, Califórnia, 2016.

HOLMES, Bev et al. Translating evidence into practice: the role of health research funders. Implementation Science, Califórnia, 2012.

IBGE. Instituto Brasileiro de Geografia e Estatística. Universo preliminar do Censo Demográfico. Rio de janeiro, 2010.

MARCONI, Marina; LAKATTOS, Eva Maria. Fundamentos da metodologia científica. São Paulo: Atlas, 2008.

MINAYO, Maria Cecilia et al. Métodos, técnicas e relações em triangulação. In: MINAYO, Maria Cecilia; ASSIS, Simone Gonlaves; SOUZA, Edinilsa Ramos. Avaliação por triangulação de métodos: abordagem de programas sociais. Rio de Janeiro: Fiocruz, p.75$104,2005$.

MORAES, Raquel; GALIAZZI, Maria do Carmo. Análise textual discursiva. Ijuí: Editora Ijuí, 2016.

PAES-SOUSA, Romulo. Plano Brasil sem miséria: incremento e mudança na política de proteção e promoção social no Brasil. Working Paper, n. 113, Brasília: Centro Internacional de Políticas para o Crescimento Inclusivo (IPC-IG), 2013.

PAES-SOUSA, Romulo; VAITSMAN, Jeni. The zero hunger and Brazil without extreme poverty programs: a step forward in brazilian social protection policy. Ciência \& Saúde Coletiva, Rio de Janeiro, v. 19, n. 11, p. 4351-4360, 2014. 
PENFIELD, Teresa et al. Assessment, evaluations, and definitions of research impact: a review. Research Evaluation, Reino Unido, v. 23, n. 1, jan. 2014.

SILVA, Antonio Ozai. A sua revista tem Qualis? Mediações, Londrina, v. 14, n.1, p. 117124, 2009.

TUESTA, Antonia de Jesus. Impactos das pesquisas sobre morbimortalidade materna e neonatal financiadas pelo Ministério da Saúde. Tese (Doutorado em Ciências da Saúde) Universidade de Brasília, Brasília, 2015.

YIN, Robert. Estudo de caso: planejamento e métodos. 2. ed. Porto Alegre: Bookman, 2001. 